\title{
Mapping Center Pivot Irrigation Fields in South Carolina with Google Earth Engine and the National Agricultural Imagery Program
}

\author{
C. Alex Pellett ${ }^{1}$
}

AUTHORS: ${ }^{1}$ Hydrologist, South Carolina Department of Natural Resources, 311 Natural Resources Drive, Clemson, SC 29631.

\begin{abstract}
Aerial images taken during the growing seasons of 2009, 2011, 2013, 2015, and 2017 were visually inspected for evidence of irrigation. Center pivot irrigation was identified by the characteristic shape of the spans and the curved tracks left by the wheels. The author manually delineated a polygon over each agricultural area where signs of irrigation infrastructure were observed. The result is a map of 2,689 polygons covering 146,662 acres in South Carolina. Compared with the United States Department of Agriculture 2017 Census of Agriculture, the sampling results account for over $69 \%$ of total irrigated area and over $98 \%$ of area irrigated solely by center pivots. Most center pivots covered from 25 to 75 acres, while the largest center pivot extended over 300 acres. These results are an important contribution to the quantification of water use in South Carolina.
\end{abstract}

\section{INTRODUCTION}

Agricultural irrigation is an important use of South Carolina's water resources, and center pivot irrigation is the predominant irrigation technique in the state. The detailed map of center pivot irrigation presented in this study is the first of its kind in South Carolina. It can be used to develop inputs for the water-demand projections and the soil-water balance model used to inform River Basin Plans across the state (SCDNR 2019).

The purpose of this article is to document this new data set and begin to evaluate its implications. The methods were designed to minimize commission error in the identification of irrigated areas, and a corresponding trade-off of relatively higher omission error is expected. In other words, irrigated areas were mapped only when clear evidence of irrigation was found, so some irrigation was certainly not mapped.

This study began using the Google Earth Engine (GEE) platform, which provides a user interface with the highresolution imagery base map of Google Earth and a variety of computational analysis functions in JavaScript programming language (Gorelick 2017). The author's original intent was to delineate a sample of irrigated areas by visual interpretation for the purpose of subsequent computational analysis (i.e., using the sample to train an automated classification algorithm).

The ease of the GEE interface facilitated delineation of a very substantial sample of center pivot irrigation-2,689 polygons covering 146,662 acres-and the success of this sampling effort prompted further investigation. The delineated polygons were overlaid on aerial images $(1 \mathrm{~m}$ spatial resolution) from the National Agricultural Imagery Program (NAIP) for the growing seasons of 2009, 2011, 2013, 2015, and 2017. Each edition of NAIP imagery was visually inspected to determine the presence or absence of evidence of irrigation at each polygon, resulting in a multiyear sample of irrigated areas.

The completeness of the resulting sample of irrigated areas is evaluated by comparison with survey-based reference data. Generally, a more complete sample can reduce uncertainty in summary statistics, but the sampling method can still cause bias. In this case, sampling irrigated areas through visual inspection has resulted in a bias toward center pivot distribution systems. Spatial attributes of center pivot distribution systems in SC (e.g., shape, area) are summarized and presented.

This information can be used to develop machinelearning algorithms to improve and expand irrigation mapping in the South-Atlantic Coastal Plain. Thorough and meticulous collection of training data is a necessary first step in the application of modern statistical tools for the purpose of monitoring and evaluating water use.

The objectives of this work are:

1. to map irrigated areas in SC,

2. to evaluate the map for completeness, and

3. to characterize spatial attributes of center pivots. 


\section{Mapping Center Pivot Irrigation Fields in South Carolina with Google Earth Engine}

\section{RELATED WORK}

Irrigated area has been quantified using surveys of irrigators and analyses of aerial and satellite imagery. Imagery analysis methods include visual identification and automated classification algorithms. Studies often combine multiple methods to assess accuracy by comparing the results.

The United States Department of Agriculture describes its Census of Agriculture (COA) as a complete count of farms and ranches in the United States (USDA NASS 2019). The COA provides estimates of irrigated acreage in each county and in 5-year intervals. The COA estimates are based on information collected through questionnaire surveys and further cross-validated using information from other federal government records. Since 2012, estimated coefficients of variation are reported for state-level data, and generalized coefficients of variation are reported for the counties in each state. The COA reports irrigation in South Carolina (SC) expanding from 88,898 acres in 1997 to 210,437 acres in 2017, while the number of irrigators rose from 1,435 to 2,167 over that time period. Coefficients of variation for this statewide data in 2017 were reported as $>20 \%$. For county-level data in SC, the generalized coefficient of variation was $47.3 \%$ for irrigated acreage and $73.7 \%$ for the number of irrigators.
The Irrigation and Water Management Survey (IWMS), formerly called the Farm and Ranch Irrigation Survey (FRIS), is sent to irrigators identified by the COA. The 2018 IWMS results include totals for SC of 1,489 irrigated farms, 252,720 irrigated acres, and 203,411 acre-feet of irrigation water. The IWMS results indicate that $88 \%$ of outdoor agricultural irrigated acreage was under sprinkler systems in 2018, up from $73 \%$ in 2013 . Most of the remainder was irrigated by drip, trickle, or low-flow micro sprinklers, and less than $5 \%$ was irrigated by gravity systems. The total acreage of center pivot sprinklers in 2018 was 205,016 acres. The next-largest reported categories of sprinklers were big-gun/ traveler sprinklers on 9,046 acres, and solid-set/permanent sprinklers on 4,258 acres. These acreage numbers may be inflated by double counting of acres covered by multiple irrigation systems. Relevant results from the IWMS and FRIS are presented in Table 1 (USDA NASS 2015, 2019).

Preliminary results from a survey of 167 farmers irrigating 75,000 acres in SC also show that a majority of respondents used center pivots-more than twice the number of respondents using any other type of irrigation system (Sawyer et al. 2018).

Irrigators in South Carolina who withdraw more than 3 million gallons of water in any month are required

Table 1. Irrigation in Open Fields in South Carolina

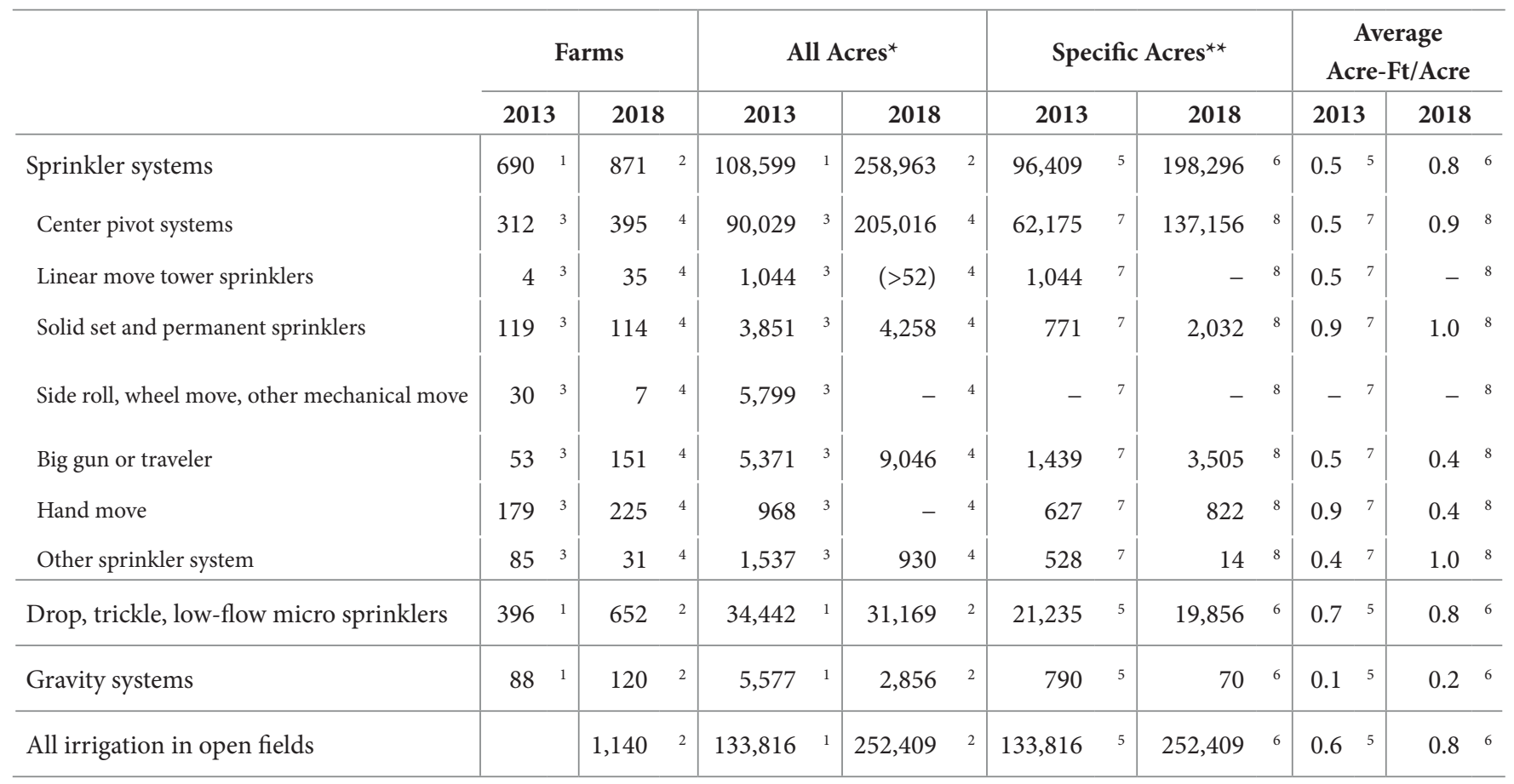

${ }^{\star}$ Multiple systems covering the same acreage are counted each time they cover the acres. This includes multiple systems of the same type.

${ }^{*}$ Specific acres are only irrigated by a single kind of distrubition system. Acres represent the acres of land with coverage by at least one of the systems. Acres are not double-counted if multiple systems exist on the same acreage.

Sources: [1] 2013 Farm and Ranch Irrigation Survey (FRIS), Table 28. [2] 2018 Irrigation and Water Management Survey (IWMS), Table 28. [3] FRIS, Table 29. [4] IWMS, Table 30. [5] FRIS, Table 32. [6] IWMS, Table 32. [7] FRIS, Table 34. [8] IWMS, Table 34. 
by law to register their withdrawal intakes and report the monthly withdrawal volume for each intake. The registration information includes latitude and longitude and the source of water. Not all irrigators are required to register (e.g., those who withdraw less than 3 million gallons per month), and it is possible that not all irrigators who are required to register have registered. Among registered and permitted water users, reporting compliance is greater than 99\%. In 2017, 444 registered agricultural irrigators reported withdrawing 157,617 acre-feet of water from streams, reservoirs, and wells in SC (Monroe 2018).

Among 158 registered irrigators in SC who responded to a 2017 survey, 30\% planned to increase their irrigation water withdrawal volume in the following 5 -year period while only $3 \%$ planned to decrease their irrigation water withdrawal volume (Pellett and Walker 2018).

Irrigated areas in other eastern states have been mapped using visual interpretation of aerial and satellite imagery. Center pivot irrigation has been mapped in the mid-Atlantic region through visual interpretation of NAIP imagery (Finkelstein and Nardi 2015). Irrigation was delineated on 272,000 acres out of an estimated 410,000 totaled in the Census of Agriculture across the region (66\%). The delineation rate was found to be especially low where subsurface or drip irrigation was prevalent.

Landsat satellite imagery (30 m spatial resolution) was used to map irrigation in the coastal plain of Georgia in 4-year increments from 1976 to 2013 (Williams et al. 2017). The results were compared with a validation data set developed using NAIP, Google Earth ${ }^{\mathrm{Ts}}$, and field-survey GPS data.
Compared to the validation data set, county scale percent coincident ranged from 40 to $80 \%$. Over time, irrigation in Georgia has expanded northeastward along the coastal plain.

Automated classification algorithms have also been applied to map irrigation using satellite imagery. The MIrADUS data set maps irrigation in MODIS satellite images. The classification algorithm used to develop MIrAD-US is calibrated using COA estimates of irrigated area by county. MIrAD-US has been produced for the entire US for years 2002, 2007, 2012, and 2017. However, the spatial resolution of MIrAD-US is $250 \mathrm{~m}$, and it has particularly low accuracy in the humid Southeast (Pervez and Brown 2010).

LANID, a Landsat-based irrigation classifier, is a more recent development (Xie et al. 2019). The first edition of LANID represents the year 2012, and it appears to be well correlated with the results of this study. An expanded edition of LANID, covering from 1997 to 2017, is expected to be published in 2020.

Survey data illustrate the prevalence of center pivot sprinklers and the ongoing expansion of irrigation in SC. Efforts to map irrigation nationally indicate that the humid southeast is a region of particular uncertainty for mapping methods based on automated algorithms. Other investigations in the eastern US demonstrate the viability of visual interpretation as a method of delineating irrigated areas. This study expands upon the body of related literature by developing a multiyear map of irrigated areas in SC using visual inspection of high-resolution imagery from NAIP

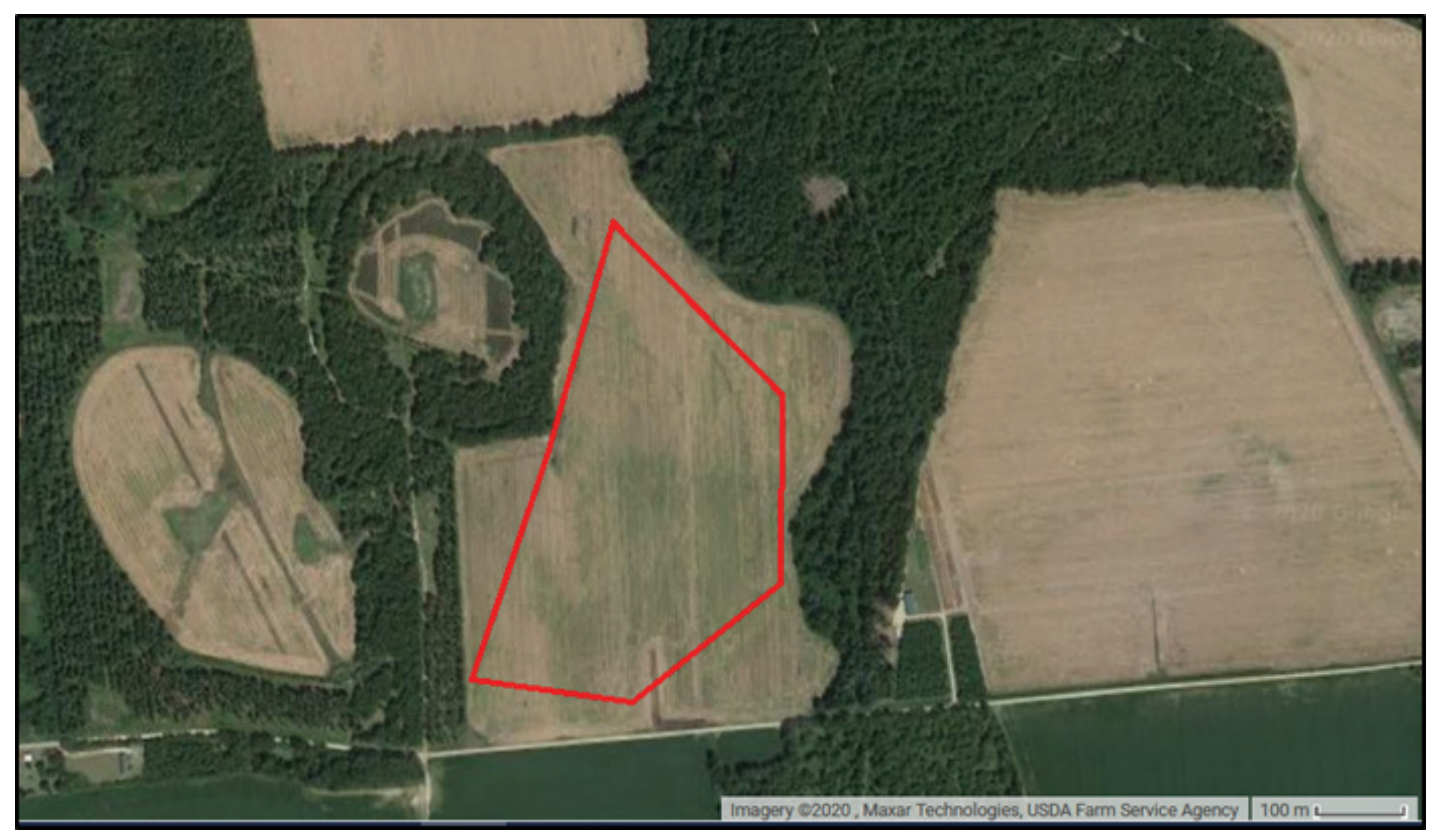

Figure 1. A screenshot from Google Earth Engine ${ }^{\mathrm{TM}}$ (GEE), showing several neighboring agricultural fields. Only one of these fields includes evidence of irrigation infrastructure, outlined by the red polygon. 


\section{Mapping Center Pivot Irrigation Fields in South Carolina with Google Earth Engine}

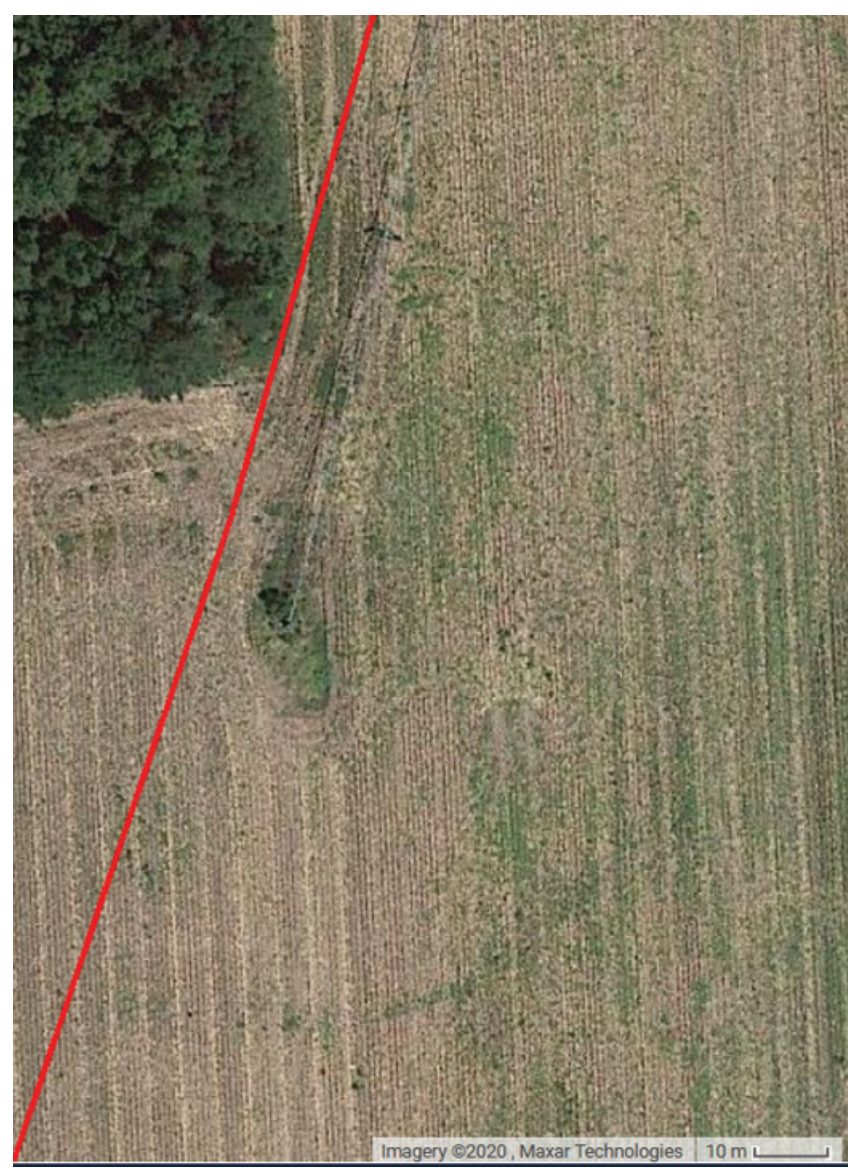

Figure 2. An up-close view of the center pivot irrigation system in Figure 1. The central pivot point $(A)$ and the first tower (B) are indicated by yellow arrows. The span is visible as a thin gray line from $A$ to $B$ and beyond the extent of this image. Each tower leaves an arc-shaped track in the field as it travels around the pivot point, and the tower at point $B$ has left a track that is faintly visible in the image.

and Google Earth. These free Internet services enabled a streamlined workflow for visual interpretation, resulting in a geographic data set encompassing a majority of irrigated areas in SC.

\section{METHODS}

Registered irrigation-water withdrawal intake locations were uploaded to GEE to start the search for irrigated areas. The Google Earth" imagery (๑ Maxar Technologies) was inspected for evidence of irrigation infrastructure, and polygons were delineated around evidently irrigated areas. Irrigation polygons from GEE were transferred to ArcMap software and overlaid onto NAIP imagery for years 2011, 2013, 2015, and 2017. The resulting multiyear data set of irrigated area over time is summarized by state and county for comparison with COA estimates. Spatial attributes of irrigation polygons were assessed using R statistical software, specifically the $s f$ package (Pebesma 2018).

\section{GOOGLE EARTH ENGINE}

GEE was used to map irrigated areas as polygons on the base map Google Earth imagery. The GEE platform provides many computational tools for sophisticated data analysis, but in this study the point-and-click interface was used simply to delineate irrigated areas as polygons. Registered irrigationwater withdrawal intakes were overlaid on the base map imagery. The polygons were identified by panning around the base map and zooming in when any of the following cues were apparent:

- Proximity to irrigation-water withdrawal intakes.

- Fields with curved circular edges.

- Fields with apparent pivot points.

- Fields appearing greener or darker than surrounding fields.

- Discolored linear traces extending from known irrigation intakes or pivot points (possibly indicating soil disturbance from the installation of underground water pipes).

- Proximity to other irrigated areas.

The above cues guided the search, but they were not sufficient to justify delineation. Irrigated areas were only delineated after identification of irrigation infrastructure (typically a visible truss system represented by a thin, lightgray line, often with towers, pivot point, and tracks clearly visible), or evidence of irrigation infrastructure (evenly spaced concentric circular tracks adjacent to tree canopy, which could mask a truss system). Figure 1 provides an example of several neighboring fields, only one of which had evidence of irrigation, shown in Figure 2. The delineated polygons correspond to the cultivated areas within the range of irrigation infrastructure, including ditches traversable by the irrigation infrastructure. Forested areas, paved roads, and wetlands were generally excluded, even where center pivots apparently passed. Areas irrigated by traveling gun or by end guns were not included in the sample.

\section{THE NATIONAL AGRICULTURAL IMAGERY PROJECT}

Next, the irrigated area polygons were overlaid on NAIP imagery (USDA). The NAIP images of 2011, 2013, 2015, and 2017 were interpreted for evidence of irrigation in each polygon. Each polygon was labeled with the year of the earliest image, which included evidence of irrigation within that polygon. Irrigation polygons were also classified as center pivot systems or other types of systems, and center pivot systems were represented with additional point features at the central hub (the pivot point). Some other types of irrigation zones (e.g., linear move) may have been misclassified as center pivot type. Some small sprinklers, orchards, and raised beds were classified as irrigation based 
on visual cues and proximity to irrigation-water withdrawal intakes.

The delineation process implemented in GEE resulted in some overlapping center pivot areas, which were merged following the initial transfer of the polygon data to shapefile format. In these cases, the resulting polygons were divided, and land was allocated to the closest center pivot point. This is in contrast to the delineation by Finkelstein and Nardi (2017), which includes overlapping polygons.

In some areas it seemed the image quality (due to resolution, contrast, or timing) improved incrementally over the years. Smaller pivots were harder to identify in the imagery. In some cases, the observation of an apparent pivot point was taken as sufficient evidence of irrigation at this stage; in other cases, the presence of indistinct marks or specs was deemed insufficient evidence.

As the original sampling in GEE was done using more recent imagery, irrigation was assumed not to have been discontinued after installation in any of the sampled zones over the 2011 to 2017 period. For a small minority of the sampled zones (presumably with irrigation infrastructure installed after 2017), no evidence of irrigation infrastructure was found in the NAIP imagery.

There were some cases where the pivot points and arrangement of irrigation infrastructure changed over time. If there was evidence of irrigation across most of the GEE- based delineation, then it was coded as existing irrigation for that year (despite changes in the setup of one or more center pivots or other kinds of irrigation within the delineated area).

\section{RESULTS}

Heads-up digitizing resulted in 2,689 polygons covering 146,662 acres in South Carolina. The results include 2,540 polygons classified as center pivots, covering 135,639 acres. This represents $98 \%$ of the acreage irrigated solely by center pivots, according the 2019 Irrigation and Water Management Survey (Table 1). Figure 3 shows the extent of the irrigation mapped in this study.

\section{SPATIAL ATTRIBUTES OF IRRIGATION POLYGONS}

Several spatial attributes of the center pivot irrigation polygons were calculated for the purpose of characterizing the spatial properties of center pivots. Figure 4 provides histograms of polygon area, length of span, and coverage efficiency.

The irrigation polygons varied greatly in size. The 3 largest, from 540 to over 1,900 acres, are not center pivots. They were delineated as aggregate irrigated areas, not as individual irrigation distribution systems. The 3 largest center pivots ranged from 330 to 440 acres, but the majority were less than 100 acres.

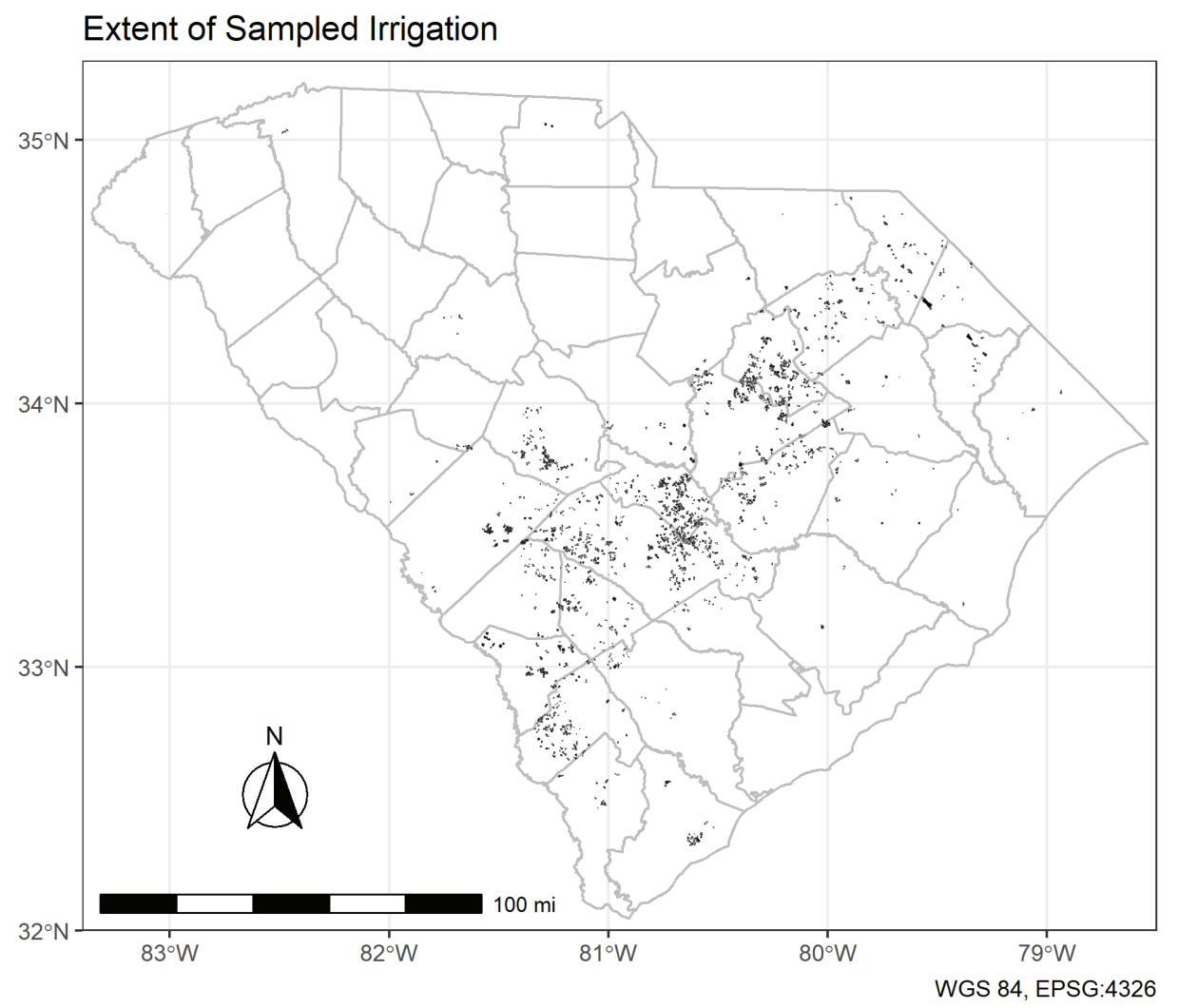

Figure 3. Irrigation polygons mapped over South Carolina using heads-up digitization on Google Earth and NAIP aerial imagery. Counties are outlined in gray. 
Histograms of Center Pivot Characteristics
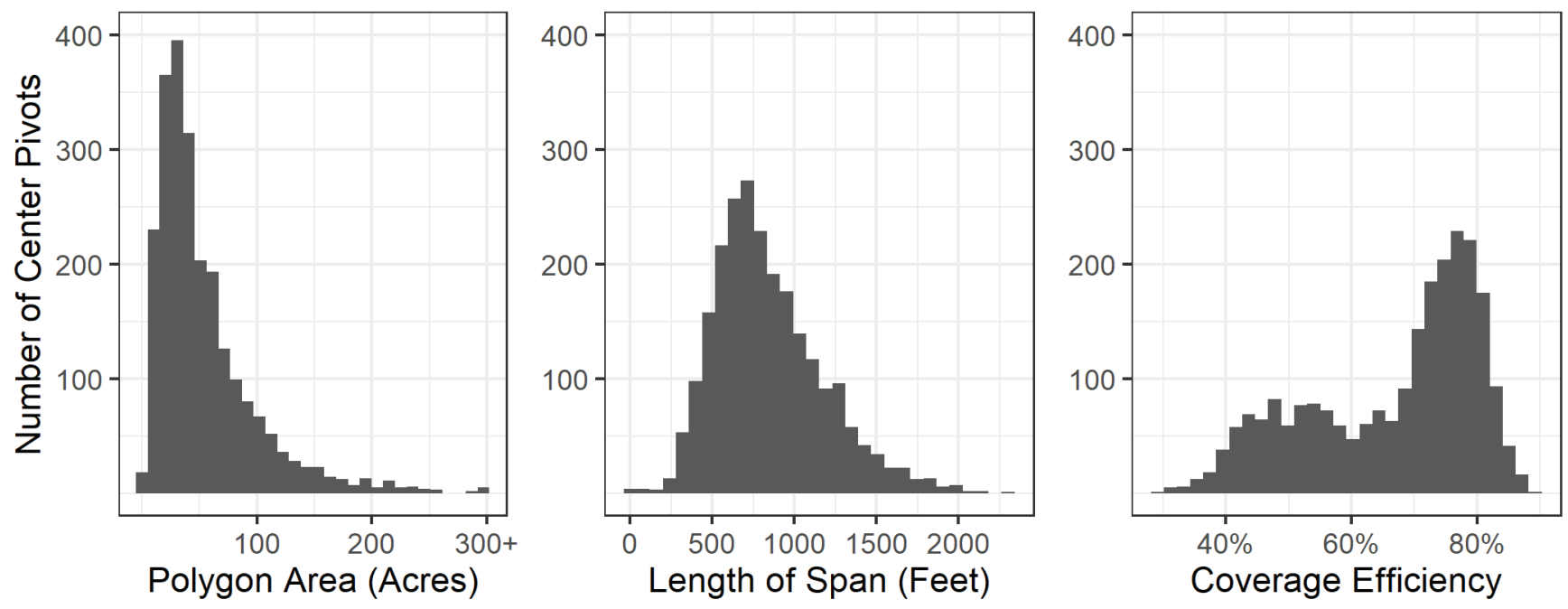

Figure 4. Several spatial characteristics of the center pivot polygons were calculated and the results are presented here as histograms. Left: Distribution of the areas of mapped center pivot polygons. Center: Distribution of the lengths of mapped center pivot spans. Right: Distribution of the coverage efficiency of mapped center pivots.

The length of the span of each center pivot was estimated as the distance from the pivot point to the nearest point on the minimum bounding circle of the center pivot polygon. Most center pivots spanned between 500 and 1,000 feet, with very few less than 250 feet and some as long as 2,000 feet or more.

The shapes of the center pivot polygons varied from circle to semicircle or wedge. For each center pivot polygon, the coverage efficiency is calculated here as the ratio of irrigated area divided by the maximum area irrigated by the estimated span. In a large, uniform field, the most cost-effective center pivot installation would complete a 360-degree rotation around the central pivot point, yielding $100 \%$ coverage efficiency. Optimal configuration in more complex terrain may include semicircle- or wedge-shaped irrigation polygons, yielding lower coverage efficiency. The histogram of center pivot coverage efficiency indicates an asymmetric, bimodal distribution. Many center pivot polygons were nearly complete circles, with coverage efficiencies greater than $75 \%$. A smaller but significant number of polygons had coverage efficiencies around $50 \%$.

\section{COMPARISON WITH THE CENSUS OF AGRICULTURE}

Figure 5 shows the mapping results with the Census of Agriculture estimates of irrigated area over time for South Carolina and the eight counties with the most reported irrigated area in 2017. In 2017, the Census of Agriculture reports 210,437 total irrigated acres in SC, while the mapping results total 146,662 acres, which is $69 \%$ of the Census total. When compared to the Census of Agriculture on a county basis, the results are more variable. In many of the counties with the most irrigation, the mapped sample seems to match the Census results well. However, in some counties the results differ widely. Among the counties shown in Figure 5, the mapped irrigation clearly underrepresents Edgefield County. Edgefield County has a lot of peach orchards, and the irrigation infrastructure in orchards was not readily apparent in the NAIP imagery.

\section{DISCUSSION}

Most center pivots were readily identifiable in the NAIP imagery, but other irrigation distribution systems were less easily mapped.

The size attributes of the sampled center pivots are relevant when evaluating the usefulness of remote sensing data sets with lower spatial resolution. While many center pivots irrigate approximately circular areas, many irrigate incomplete circles. Image classification algorithms can be programmed to identify circular features, but for this application they would need to be robust enough that noncircular irrigation is also classified correctly.

It is unlikely that every single center pivot was identified. Furthermore, end guns are often attached to the mobile end of each center pivot, expanding the range of irrigation beyond the extent of the span. Therefore, it is likely that there is more area irrigated by center pivots than this study represents.

It is therefore unexpected that more irrigation was mapped in some counties than is included in the Census of Agriculture. False positives in the mapped sample could result from irrigation infrastructure that was not actually utilized in a given year. Alternatively, underreporting may 


\section{Census of Agriculture and Mapped Irrigation Over Time}

\section{In South Carolina and Selected Counties}
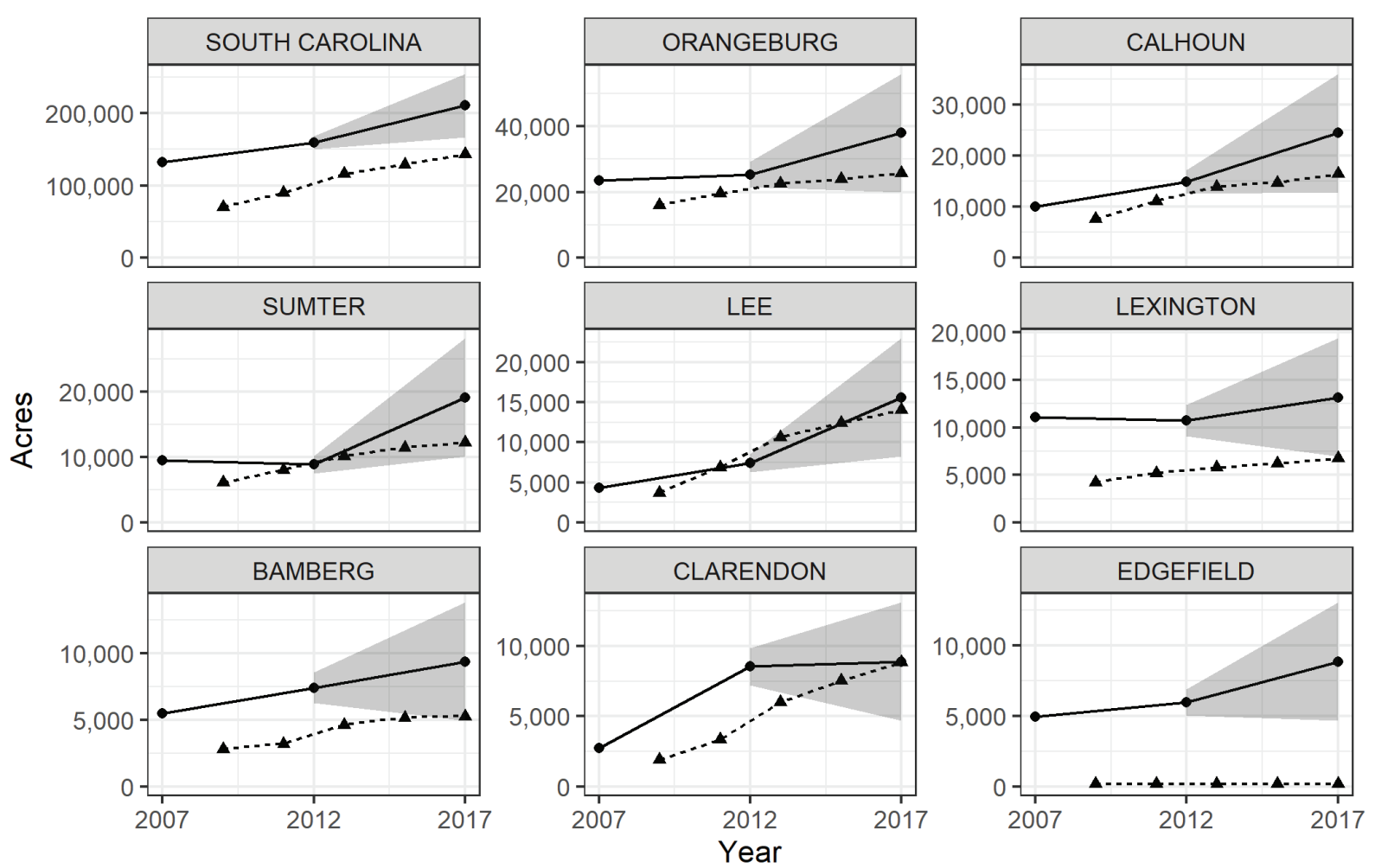

Census of Agriculture (USDA, 2019) - Mapping Results

Figure 5. A comparison of irrigated area from the Census of Agriculture and the mapped sample, for the entire state and on a county basis for selected counties. The shaded area represents the confidence interval calculated from the coefficients of variation reported in the Census of Agriculture.

cause the Census of Agriculture results to underestimate irrigated area.

\section{RECOMMENDATIONS FOR FUTURE WORK}

The sample of irrigated areas developed in this study can be used for a variety of analyses. Spatial overlays with other relevant data sets can be used to further characterize irrigation in SC. Information from water withdrawal registrations can be combined with mapped irrigation to evaluate irrigation water demand on a per-acre basis.

Automated classification algorithms can provide improved results with additional reliable training data. The results of this project have been shared with the developers of two ongoing national irrigation projects, MIrAD-US and LANID, with the hope of improving the accuracy of irrigation mapping in SC.

The data set could be enhanced by more precise mapping of features within and around the irrigation polygons: the extent of land irrigated by end guns, the subset of irrigated area that is cultivated, classification of irrigated crops, and so forth. The method employed in this project could also be employed to map greenhouses, which are readily identifiable in the NAIP imagery and are generally irrigated.

\section{LITERATURE CITED}

Finkelstein JS, Nardi MR. 2015. Geospatial compilation and digital map of center pivot irrigated areas in the midAtlantic region, United States. U.S. Geological Survey Data Series 932, https://doi.org/10.3133/ds932. ISSN 2327-638X.

Gorelick N, Hancher M, Dixon M, Ilyushchenko S, Thau D, Moore R. 2017. Google Earth Engine: Planetary-scale geospatial analysis for everyone. Remote Sensing of Environment 202. 18-27.

Monroe LA. 2018. South Carolina water use report 2017 summary. Columbia: South Carolina Department of Health and Environmental Control, Bureau of Water.

Pellett, CA, Walker, T III. 2018. Water Users' perspectives: summary of withdrawal survey responses and 
commentary. Journal of South Carolina Water Resources. 5:1:Article 3. https://doi.org/10.34068/JSCWR.05.03

Pebesma E. 2018. Simple Features for R: Standardized Support for Spatial Vector Data. The R Journal. 10(1):439446. 10.32614/RJ-2018-009, https://doi.org/10.32614/ RJ-2018-009.

Pervez MS, Brown JF. 2010. Mapping irrigated lands at 250$\mathrm{m}$ scale by merging MODIS data and national agricultural statistics. Remote Sensing. 2010; 2(10):2388-2412. https:// doi.org/10.3390/rs2102388.

Sawyer CB, Allen JS, Smith M, Walker TC, Willis D, Dobbins T, Phinney D, Morganello KC, Smith B, Payero J, Kantrovich A, Smith N. 2018. Agricultural Water Use in South Carolina: Preliminary Results of the South Carolina Agricultural Water Use and Irrigation Survey. Presentation to the South Carolina Water Resources Conference, 17 Oct. 2018.

SCDNR. 2019. South Carolina state water planning framework. Columbia: South Carolina Department of Natural Resources.

USDA NASS 2015. Farm and Ranch Irrigation Survey. United States Department of Agriculture.

USDA NASS 2019. Census of Agriculture. Washington, DC: United States Department of Agriculture, National Agricultural Statistics Service.

Williams MD, Hawley CMD, Madden M, Shepherd HM. 2017. Mapping the Spatio-Temporal Evolution of Irrigation in the Coastal Plain of Georgia, USA. Photogrammetric Engineering \& Remote Sensing.

Xie Y, Lark TJ, Brown JF, Gibbs HK. 2019. Mapping irrigated cropland extent across the conterminous United States at $30 \mathrm{~m}$ resolution using a semi-automatic training approach on Google Earth Engine. ISPRS Journal of Photogrammetry and Remote Sensing. 155:136-149. 